\title{
FORMULATION AND CLINICAL TESTING OF GLYCERYL TRINITRATE OINTMENT FOR TREATMENT OF ANAL FISSURES
}

\author{
${ }^{1}$ Ali Ibrahem Khaleel, ${ }^{1}$ Harith Jameel Mahdi, \\ ${ }^{2}$ Emad Mothana Yousif and ${ }^{3}$ Shathel K. Noaman \\ ${ }^{1}$ Department of Pharmaceutical Sciences, \\ ${ }^{2}$ Department of Pharmaceutical Chemistry, \\ ${ }^{3}$ Department of Clinical Pharmacy, \\ Faculty of Pharmacy, University of Tikrit-Sallahuden, Iraq
}

Received 2012-07-22, Revised 2012-08-12; Accepted 2012-09-01

\begin{abstract}
Until know surgical intervention considered to be the cornerstone for treatment of anal fissure condition. Regarding all the circumstances that hinder the possibility of accomplishment of surgical operation and the possible post-urgical complications; all that motivates the necessity for a non-surgical procedure for treatment of anal fissure. This study was designed to establish a pharmaceutically active and chemically and physically stable formula of $0.4 \%$ (w/w) glyceryl trinitrate ointment. High Performance Liquid Chromatography (HPLC) was used to assay the active ingredient and to determine the rate of release of glyceryl trinitrate from the prepared ointment base. After establishing the formula, the prepared ointment was clinically tested on selected patients under supervision of specialized surgeons. After 3 months monitoring of a small scale pilot batch of $0.4 \%$ glyceryl trinitrate ointment and depending on Accelerated stability method, a physically and chemically stable formula was achieved with an unaltered $\mathrm{pH}$ and with a release rate value range between $83.4-85.1 \%$. Up to 6 months of clinical follow up shows a variation in responses from complete healing to moderate relief of symptoms. Glyceryl trinitrate shows a high rate of healing for both acute and chronic anal fissures with tolerable side effect. A significant rate of pain relief and a high rate of complete healing lead to a conclusion of effectiveness of glyceryl trinitrate as a nonsurgical treatment of both chronic and acute anal fissure.
\end{abstract}

Keywords: Glyceryl Trinitrate, Chronic Anal Fissure, Acute Anal Fissure, High Performance Liquid Chromatography (HPLC)

\section{INTRODUCTION}

Anal fissure is a superficial tear in the mucosa of the distal anal canal of a triangular shaped area of ulceration and inflammation characterized by pain on defecation, rectal bleeding and spasm of the anal sphincter (Sweetman, 2009; Stevens and Lowe, 2000).

Most fissures (about 85\%) are located dorsally. Ventral fissures are less common (10\%) and frequently occur in women while lateral fissures occur in about $5 \%$ (Outryve, 2006). Anal fissure classified to Acute and Chronic anal fissure. Acute fissures are superficial and heal spontaneously or after treatment in more than $50 \%$ of the cases, while chronic fissures are profound; occur 4-6 weeks after the initial lesion which considered as ischemic ulcers and do not heal spontaneously (Outryve, 2006). The cause is not known in the most cases but high incidence occurs in women during pregnancy and after labour, after severe long term constipation in both male and female and in people in which their jobs involves long term of uncomfortable set such as taxi drivers and office employees (Stevens and Lowe, 2000). The anodermal blood flow rates correlated inversely with the anal resting pressures. Patients with fissures had the

Corresponding Author: Harith J. Mahdi, Department of Pharmaceutical Sciences, Faculty of Pharmacy, University of Tikrit-Sallahuden, Iraq 
highest resting pressures and also the lowest perfusion rates (Dhawan and Chopra, 2007). The traditional method to treat chronic anal fissures is by surgical division of the internal anal sphincter in order to reduce anal canal pressure (Evans et al., 2003).

Healing may be promoted by conservative management with bran and bulk laxatives with application of topical local anaesthetics for pain relief (Leong, 2003). Non-surgical treatment of anal fissure involves using smooth muscle relaxation as it has advantages over surgical treatment in avoiding long term complications. Additionally, it does not require hospitalization (Dhawan and Chopra, 2007). The discovery of pharmacological agents that cause smooth muscle relaxation such as Glyceryl trinitrate, Botulinum (Sweetman, 2009) and Diltiazem (Jonas et al., 2002) which effectively heal most fissures has led to approximately two-thirds of patients avoiding surgery (Dhawan and Chopra, 2007). These medicinal substances act as inhibitory neuro-transmitter involved in relaxation of the sphincter presents a possible alternative treatment (McCallion and Gardiner, 2001; Evans et al., 2003).

Glyceryl Trinitrate, which also called Nitroglycerin, Nitroglycerol and Trinitroglycerin (Sweetman, 2009; Moffat et al., 2004), is a 1, 2, 3-propanetriol trinitrate $\left(\mathrm{C}_{3} \mathrm{H}_{5} \mathrm{~N}_{3} \mathrm{O}_{9}\right)$, was first synthesized in 1846 by Sobrero who observed that a small quantity placed on the tongue elicited a severe headache. Glyceryl trinitrate is classified as anti-anginal vasodilator drug (Katzung, 2001) and considered as a precursor of nitric oxide (Dhawan and Chopra, 2007) which is responsible for reduction of the level of $\left(\mathrm{Ca}^{+2}\right)$ and lead to the relaxation of smooth muscle in wide range of tissues (Brunton et al., 2007) but the exact mechanism of denitration of organic nitrates to liberate nitric oxide remains an active area of investigation. In smooth muscle, the net result is reduced phosphorylation of myosin light chain, reduced $\mathrm{Ca}^{+2}$ concentrations in the cytosol and relaxation in all smooth muscles (Brunton et al., 2007). Because of glyceryl trinitrate ability to relax smooth muscle of the anal sphincter, it is used in the treatment of chronic anal fissures. Recent clinical studies with topical application of suitable glyceryl trinitrare preparations have been shown to be effective (Evans et al., 2003; Lund and Scholefield, 1997) although systematic review considered that surgery is more effective than alternative medical treatment (Nelson, 2004). Glyceryl trinitrate produces healing of the chronic anal fissures and adequate symptomatic relief (Tankova et al., 2009) and should be considered as the first line treatment for anal fissure condition. In a study by Stevens and Lowe (2000), they concluded that anupsurge dosage of glyceryl trinitrate from 0.2 to 0.6 by $0.1 \%$ weekly increments was associated with a consistently lower pain score and better healing rate. In anther study it was found that $0.6 \%$ glyceryl trinitrate ointment concentration has no additional benefit over $0.2 \%$ concentration (Nelson, 2004). because of the above mentioned information, a $0.4 \%(\mathrm{w} / \mathrm{w})$ glyceryl trinitrate ointment concentration was selected to this study.

\section{MATERIALS AND METHODS}

\subsection{Materials Used to Prepare the Ointment Base}

All the materials and active constituent used were pharmaceutical grade ingredients and purchase from local market. The materials are glyceryl trinitrate (diluted with propylene glycol $10 \%$ ), Yellow soft paraffin, Hard paraffin, Liquid paraffin, Anhydrous wool alcohol (Lanoline), Polyethylene glycol 400 and dL-alpha Toccophyrol acetate.

\subsection{Equipments Used to Prepare the Ointment}

The following equipments were used for preparation of small scale pilot batch: stainless steel container, water bath, autoclave, electrical mixer, colloidal mill.

\subsection{Equipments and Reagents Used for Evaluation of the Prepared Ointment}

The assay of glyceryl trinitrate ointment was performed applying HPLC method based on British Pharmacopeia, 2004 with some modifications. The evaluation required the following: HPLC system, electronic balance, conical flask, water bath, electrical shaker, $0.4 \mu \mathrm{M}$ filter, acetonitrile and deionised water.

The chromatographic procedure was carried out using the following conditions:

- A stainless steel column $(25 \mathrm{~cm} \times 4.6 \mathrm{~mm}) \mathrm{x}$

- The mobile phase: (40:60) volumes of (acetonitrile: water)

- Flow rate: $1 \mathrm{ml} / \mathrm{min}$

- Detector: $210 \mathrm{~nm}$

\section{RESULTS}

\subsection{Physical Description}

Yellow homo-geneous oily mass with a characteristic odour.

\subsection{Identification of Active Ingredient}

The identification of the glyceryl trinitrate active ingredient in the prepared ointment was done by comparing the retention time of the peak of sample with the peak of standard Fig. 1 and 2. 
Ali Ibrahem Khaleel et al. / American Journal of Pharmacology and Toxicology 7 (3) (2012) 89-93

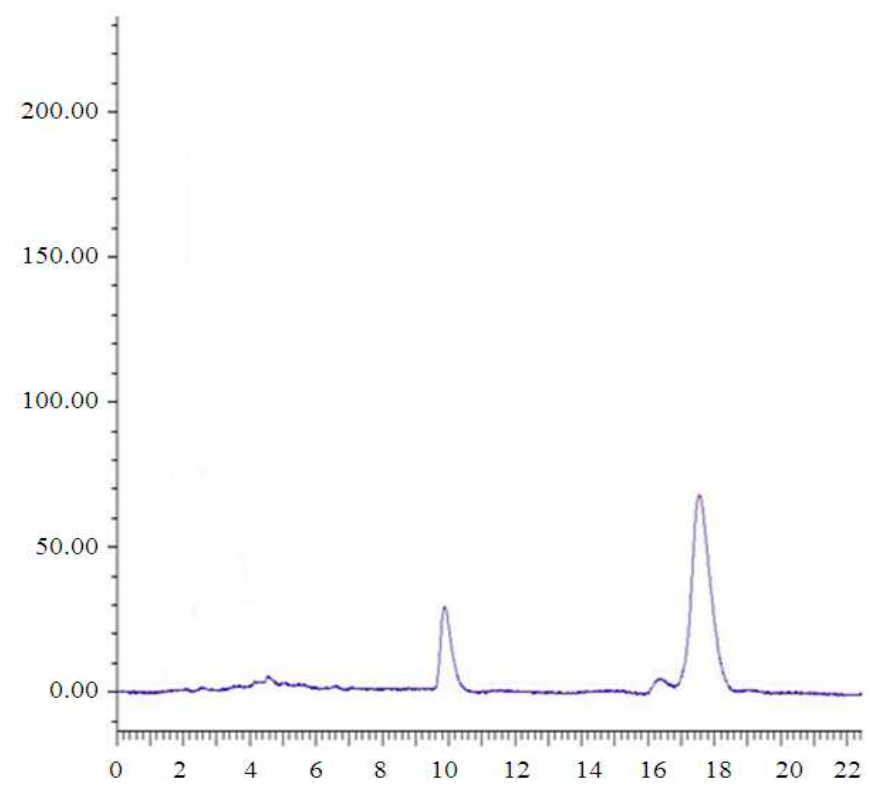

Fig. 1. The HPLC chromatogram of the standard glyceryl trinitrate

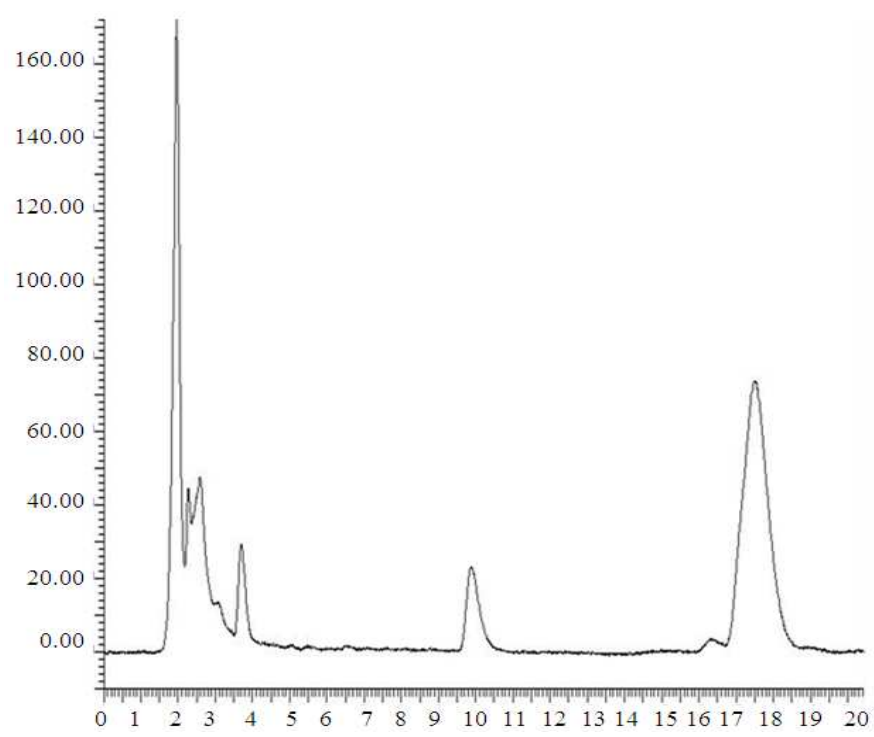

Fig. 2. The HPLC chromatogram of the prepared glyceryl trinitrate ointment

Table 1. The HPLC results of standard and released glyceryl trinitrate from ointment sample

\begin{tabular}{llllll}
\hline \multicolumn{5}{l}{ Standard } & \multicolumn{3}{l}{ Sample } \\
Time & - Retention time $(\mathrm{min})$ & Peak area $(\mu \mathrm{V} . \mathrm{s})^{*}$ & Retention time $(\mathrm{min})$ & Peak area $(\mu \mathrm{V} . \mathrm{s})$ & Assay $(\%)$ \\
\hline At preparation & 17.62 & 9604301 & 17.52 & 8125238.0 & 84.6 \\
After 1 month & 17.52 & 9530211 & 17.54 & 7948195.9 & 83.4 \\
After 2months & 17.57 & 9683150 & 17.53 & 8240360.6 & 85.1 \\
After 3months & 17.61 & 9672261 & 17.57 & 8014435.4 & 82.8 \\
\hline
\end{tabular}

- $\mu$ V.s: microvolt . second 
Table 2. Results of the clinical studies carried out using $0.4 \%$ glyceryl trinitrate ointment

\begin{tabular}{lllllll}
\hline & $\begin{array}{l}\text { No. of patients } \\
\text { studied }\end{array}$ & $\begin{array}{l}\text { No. of patients } \\
\text { healed }\end{array}$ & $(\%)$ & $\begin{array}{l}\text { No. of patients with } \\
\text { significant response }\end{array}$ & $\begin{array}{l}\text { No. of patients } \\
\text { with no response }\end{array}$ & Side effect \\
\hline Chronic & $\begin{array}{l}19 \text { (6 Females } \\
\text { and 13 males) }\end{array}$ & 6 & 31.5 & 9 & 4 & $\begin{array}{l}8 \text { with mild headache, 3 with } \\
\text { headache and 1 with anal itching } \\
\text { Acute with headache, 1 with nausea and } \\
\text { 4 with mild headache }\end{array}$ \\
\hline $\begin{array}{l}17 \text { (3 females } \\
\text { and 14 males) }\end{array}$ & 11 & 64.7 & 6 & - & \\
\hline
\end{tabular}

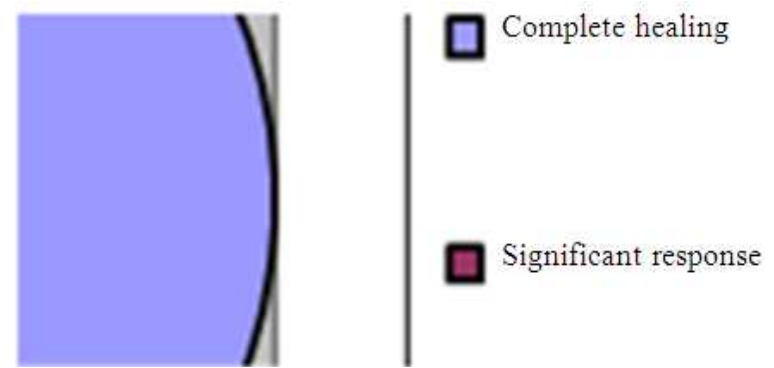

Fig. 3. Responses of patients with Acute anal fissure to treatment with $0.4 \%(\mathrm{w} / \mathrm{w})$ Glyceryl trinitrate ointment
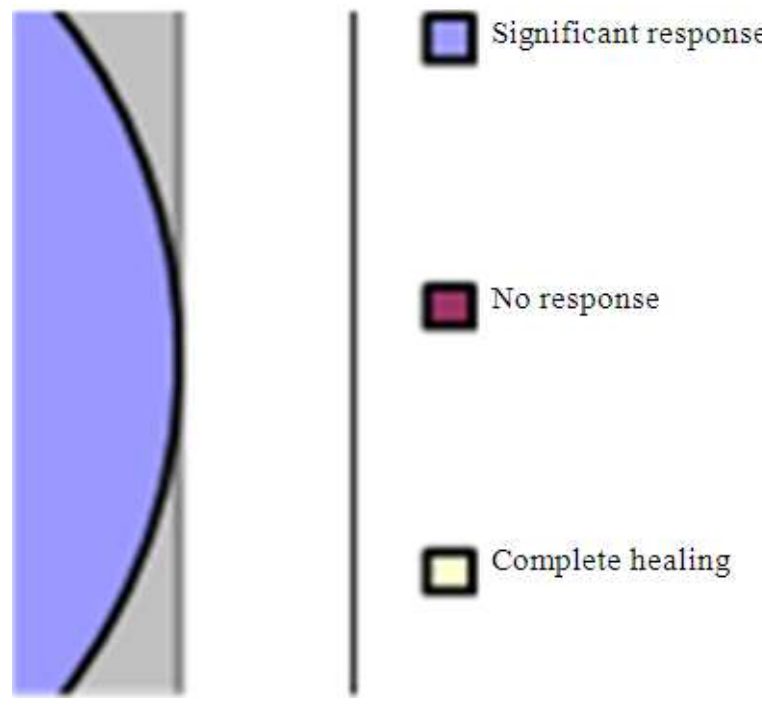

Fig. 4. Responses of patients with Chronic anal fissure to treatment with $0.4 \%(\mathrm{w} / \mathrm{w})$ Glyceryl trinitrate ointment

\section{3. $\mathrm{pH}$ of the Ointment:}

$$
5.4 \text { (limit : } 5-6)
$$

\subsection{Stability Study and Shelf Life}

The prepared ointment was found to be chemically and physically stable. By applying of Arrhenius equation, the expiry date of the prepared ointment was calculated to be more than 2 years.

\subsection{Release Rate}

The release rate was determining In-vitro and the extracted quantity of Glyceryl trinitrate was assayed using HPLC technique. The release rate value was found to be range between 82.8 and $84.6 \%$ of the labeled amount Table 1.

\subsection{Selection of Patients}

All patients were clinically examined and visual inspection to be acute or chronic anal fissure cases by specialized surgeons.

\subsection{Clinical Test}

The prepared ointment was clinically tested on 36 patients (32 adults and 4 children) with anal fissure. The cases include 19 patients with chronic anal fissure and 17 patients with acute anal fissure condition. The duration of treatment was up to 3 months for acute anal fissure and up to 6 months for chronic anal fissure with $1.5 \mathrm{gm}$ ointment applies twice daily. The responses were varied from complete healing to no response Fig. 3 and 4 . Numbers of patients expressed side effects includes headache, light head, anal aching and discomfort Table 2.

\section{DISCUSSION}

The prepared ointment shows no remarkable changes in color or odor during the period of storage and examination with a $\mathrm{pH}$ change within the limit.

The results of the assay illustrate the stability of the active ingredient while the $\mathrm{pH}$ indicates the stability and compatibility of the formula used to prepare the ointment. In addition to that, the detected results show the suitability of the formula for large scale production. However, a more monitoring and observation period are needed to confirm the stability and activity of the ointment. A more research is needed to establish a large scale production procedure.

For detection of stability and determination of shelflife, the prepared ointment was divided into three samples and each sample was stored in stability incubator at specified temperature $\left(30,40,50{ }^{\circ} \mathrm{C}\right)$ and $35 \%$ relative humidity. Accelerated stability study 
method was used for 3 months with two weeks interval for sample detection.

The addition of propylene glycol 400 to the oily base leads to improvement of the release rate and consequently availability of the active ingredient to demonstrate the healing effect.

All the patients expressed a significant pain relieve from the first dose but a variation in healing were recorded among them.

\section{CONCLUSION}

A stable and pharmacologically active ointment formula was established with a good release rate and an admirable clinical response of patients.

Acute anal fissure cases shows higher healing rate and shorter treatment duration than chronic anal fissure cases. Additionally, young people show more tendencies for complete healing than older one. In the other hand, there is no enough information about the variations in response to treatment between male and female.

\section{ACKNOWLEDGEMENT}

The researchers would like to thanks Dr. Maan A. Adory, head of Department of Surgery, Samarra General Hospital and Dr. Basim Gd. Alsamarrai, specialist G.I.T. Surgeon, Samarra General Hospital for their appreciate cooperation and following up the cases. Also the authors are grateful to all the workers in Quality Control Department, The state Company for Drug Industry and Medical Appliances (SDI), Samarra-Iraq, for their help in monitoring the prepared ointment.

\section{REFERENCES}

Brunton, L., D. Blumenthal, I. Buxton and K. Parker, 2007. Goodman and Gilman's Manual of Pharmacology and Therapeutics. 1st Edn., McGrawHill Prof Med/Tech, New York, ISBN-10: 0071443436, pp: 642.

Dhawan, S. and S. Chopra, 2007. Nonsurgical approaches for the treatment of anal fissures. Am. J. Gastroenterol., 102: 1312-1321. PMID: 17531031
Evans, B., K. Pothecary, L. Hutchings and J. Rhodes, 2003. The formulation, analysis and stability of glyceryl trinitrate in non-aqueous pharmaceutical formulations. Pharmaceutical. J., 270: 482-484.

Jonas, M., W. Speake and J.H. Scholefield, 2002. Diltiazem heals glyceryl trinitrate-resistant chronic anal fissures: A prospective study. Dis. Colon Rectum, 45: 1091-1095. PMID: 12195195

Katzung, B.G., 2001. Basic and Clinical Pharmacology. 8th Edn., McGraw-Hill, New York, ISBN-10: 0838505988, pp: 1217.

Leong, A.P., 2003. Pharmacological treatment of anal fissure--a future role in primary care. Singapore Med. J., 44: 136-137. PMID: 12953727

Lund, J.N. and J.H. Scholefield, 1997. A randomised, prospective, double-blind, placebo-controlled trial of glyceryl trinitrate ointment in treatment of anal fissure. Lancet, 349: 11-14. PMID: 8988115

McCallion, K. and K.R. Gardiner, 2001. Progress in the understanding and treatment of chronic anal fissure. Postgrad. Med. J., 77: 753-758. DOI: 10.1136/pmj.77.914.753

Moffat, A.C., M.D. Osselton, B. Widdop and E.G.C. Clarke, 2004. Clarke's Analysis of Drugs and Poisons: In Pharmaceuticals, Body Fluids and Postmortem Material. 3rd Edn., Pharmaceutical Press, London, ISBN-10: 0853694737, pp: 1931.

Nelson, R., 2004. A systematic review of medical therapy for anal fissure. Dis. Colon Rectum, 47: 422-431. PMID: 14994109

Outryve, M.V., 2006. Physiopathology of the anal fissure. Acta Chir Belg., 106: 517-518. PMID: 17168260

Stevens, A. and J.S. Lowe, 2000. Pathology. 2nd Edn., Mosby, Edinburgh, ISBN-10: 0723432007, pp: 652.

Sweetman, S.C., 2009. Martindale: The Complete Drug Reference. 36th Edn., Pharmaceutical Press, ISBN10: 0853698406, pp: 3694.

Tankova, L., K. Yoncheva, D. Kovatchki and I. Doytchinova, 2009. Topical anal fissure treatment: Placebo-controlled study of mononitrate and trinitrate therapies. Int. J. Colorectal Dis., 24: 461464. PMID: 19137320 